\title{
GABAergic Inhibition Antagonizes Adaptive Adjustment of the Owl's Auditory Space Map during the Initial Phase of Plasticity
}

\author{
Weimin Zheng and Eric I. Knudsen \\ Department of Neurobiology, Stanford University School of Medicine, Stanford, California 94305-5125
}

\begin{abstract}
We studied the influence of GABA-mediated inhibition on adaptive adjustment of the owl's auditory space map during the initial phase of plasticity. Plasticity of the auditory space map was induced by subjecting owls to a chronic prismatic displacement of the visual field. In the initial stages of plasticity, inhibition suppressed responses to behaviorally appropriate, newly functional excitatory inputs. As a result, adaptive changes in excitatory input were only partially expressed as postsynaptic spike activity. This masking effect of inhibition on map plasticity did not depend on the activity of NMDA receptors at the synapses that supported the newly learned responses. On the basis of these results, we propose that the
\end{abstract}

The functional properties of networks in the brain can be adjusted to accommodate the changing experience of the individual. Experience is particularly influential during sensitive periods in development, when appropriate patterns of functional connectivity are selected from wide varieties of potential patterns (Fox, 1992; Doupe and Kuhl, 1999; Issa et al., 1999; Iyengar et al., 1999; King, 1999; Knudsen, 1999; Kakizawa et al., 2000). Important factors that constrain adaptive plasticity include the spatial extent of excitatory connections and the capacity for synapses to change their strength (Kirkwood et al., 1995, 1996; Nordeen, 1997; Rhoades et al., 1997; Kakizawa et al., 2000). Dramatic decreases in either of these factors during development may contribute to the closing of sensitive periods.

This study demonstrates the contribution of another factor, GABAergic inhibition, in constraining adaptive plasticity in the brain. The effect of inhibition on adaptive plasticity was investigated in the external nucleus of the inferior colliculus (ICX) during experience-driven modification of the auditory space map. In the barn owl, the ICX is a site where the auditory system integrates frequency-specific information about sound localization cues, such as interaural time differences (ITDs) and interaural level differences (ILDs), to create a map of auditory space (Knudsen and Konishi, 1978). Experience shapes the tuning of ICX neurons for these cues so that the map of space remains accurate and appropriate for the individual, despite changes in

\footnotetext{
Received Dec. 12, 2000; revised March 13, 2001; accepted March 21, 2001.

This work was supported by a McKnight Foundation grant and National Institute on Deafness and Other Communication Disorders Grant 5 R01 DC00155-20 to E.I.K., and by an Individual National Research Service Award, National Institutes of Health, F32 DC00307-02 and a Dean's Postdoctoral Fellowship, Stanford University School of Medicine to W.Z. We thank Phyllis Knudsen for technical support throughout this study, and Peter Hyde, Will DeBello, Yoram Gutfreund, and Brie Linkenhoker for critical review of this manuscript.

Correspondence should be addressed to Dr. Weimin Zheng, Department of Neurobiology, Sherman Fairchild Science Building, Stanford University School of Medicine, Stanford, CA 94305-5125. E-mail: wzheng@stanford.edu.

Copyright (C) 2001 Society for Neuroscience $0270-6474 / 01 / 214356-10 \$ 15.00 / 0$
}

pattern of feedforward inhibition is less dynamic than the pattern of feedforward excitation at the site of plasticity. As a result, initially in the adjustment process the preexisting pattern of feedforward GABAergic inhibition opposes changes in the auditory space map and tends to preserve the established response properties of the network. The implications of this novel role of inhibition for the functional plasticity of the brain are discussed.

Key words: experience-dependent plasticity; sensitive period; inferior colliculus; bicuculline; APV-5; NMDA receptor; $\mathrm{GABA}_{A}$ receptor; iontophoresis

the cue values or in the encoding of the cue values that may occur with growth and aging (Knudsen, 1999). The effect of experience in shaping the representation of sound localization cues is most dramatic during a sensitive period that occurs early in life (Knudsen and Knudsen, 1990; Brainard and Knudsen, 1998). Beyond the sensitive period, the functional properties of ICX neurons are much less susceptible to the influence of experience.

The factors that constrain the adaptive plasticity of ICX neurons are unknown. Inhibition mediated by GABA has been suggested to contribute to the closing of sensitive periods in the visual cortex (Kirkwood et al., 1995; Hensch et al., 1998; Huang et al., 1999; Katz, 1999; Lein et al., 1999; Fagiolini and Hensch, 2000; Feldman, 2000). In the ICX of barn owls, GABAergic inhibition plays a critical role in creating and shaping the auditory space map (Fujita and Konishi, 1991; Albeck, 1997; Mori, 1997). Recently, we reported that after long periods of adaptation to prismatic displacement of the visual field, inhibition mediated through $\mathrm{GABA}_{\mathrm{A}}$ receptors was adjusted to selectively suppress responses to behaviorally inappropriate, normal excitatory input and thereby to enhance adaptive changes of the auditory map (Zheng and Knudsen, 1999). In the current study, we find that in the initial stages of map plasticity GABA-mediated inhibition has the opposite effect: it selectively suppresses responses to behaviorally appropriate, newly acquired excitatory input and thereby opposes adaptive changes of the auditory map. Although previous studies have shown that the newly functional inputs depend differentially on NMDA receptor currents (Feldman et al., 1996; Feldman and Knudsen, 1998b) and that these currents can be particularly sensitive to inhibition (Nowak et al., 1984; Feldman and Knudsen, 1998a; Isaac et al., 1999; Nicoll and Malenka, 1999), the antagonizing effects of inhibition on responses to newly functional inputs persisted even when NMDA receptors were blocked. These findings indicate that initially in the adjustment process, forces that preserve map stability and precision are in conflict with those that drive adaptive plasticity. This conserva- 
tive influence of GABAergic inhibition masks the true extent of experience-driven adjustments of excitatory input and therefore serves as a barrier to functional plasticity in mature neural networks.

\section{MATERIALS AND METHODS}

Rearing conditions. Fourteen barn owls (Tyto alba) were used in this study: 4 were raised normally, and 10 were raised wearing Fresnel prismatic lenses (VisionCare/3M) that displaced the visual field horizontally by $23^{\circ}$ to the left or right. The lenses were mounted in spectacle frames that were secured with a bolt cemented to the skull at $60-70 \mathrm{~d}$ of age, the age at which these owls are fully grown and leave the nest. The communal flight room in which they lived provided them with a rich visual and auditory environment. The experimental protocol was approved by the animal care and use committee at the Stanford University School of Medicine.

Extracellular recording and iontophoresis. Electrophysiological experiments began after 1-2 weeks of prism experience. Once experiments began, they were repeated, usually on a biweekly basis for several months. The owls were prepared for repeated neurophysiological recording as described previously (Brainard and Knudsen, 1993). All surgeries were performed while the owls were anesthetized with $1.5 \%$ halothane in a 55:45 mixture of oxygen/nitrous oxide. Bolts for mounting the spectacle frames and for securing the head in a stereotaxic apparatus were cemented to the skull, and a craniotomy was opened over the ICX. The exposed dura was covered with antibiotic ointment, the craniotomy was sealed with dental acrylic, and wounds were infused with lidocaine hydrochloride (2\%; Abbott Laboratory, North Chicago, IL). After full recovery from anesthesia, the owl was returned to its home flight room. On the day of an experiment, the owl was anesthetized, positioned, and secured to a stereotaxic frame in a sound-attenuating chamber, and the craniotomy was opened. At this point, halothane was discontinued, and oxygen/nitrous oxide was continued. The owls remained calm for the duration of the recording sessions. At the end of each experiment, the craniotomy was sealed, and the owl was returned to its home flight room.

Five-barrel glass microelectrodes were used for recording neuronal activity and iontophoresing chemical agents. The central barrel of the microelectrode contained a carbon fiber, $7 \mu \mathrm{m}$ in diameter, used to record neuronal responses. The remaining four barrels had tips 2-5 $\mu \mathrm{m}$ in diameter and were used to deliver chemical agents. Multi-units (typically 3-5 units) were selected with a slope-amplitude window discriminator (BAK Electronics, Rockville, MD). Although we consistently selected the largest unit waveforms in all recording sites, we do not know the degree to which these waveforms corresponded to the discharges of single neurons. Site response properties (i.e., tuning for frequency, ITD, and ILD) and the progression of these properties as the electrode advanced through the nucleus were used to determine that the recording sites were in the ICX (Brainard and Knudsen, 1993).

Auditory measurements. Auditory response properties of ICX sites were characterized as described previously (Brainard and Knudsen, 1993). Briefly, broadband (4-12 kHz) noise bursts (50 msec duration, 0 msec rise-fall time) were generated digitally and presented dichotically through earphones positioned at the center of the ear canals, $\sim 5 \mathrm{~mm}$ from each eardrum. The optimal values for ITD and ILD were determined for each recording site by testing, alternately, ITD tuning while holding ILD constant and ILD tuning while holding ITD constant. Once the optimal values of ITD and ILD were established, response threshold was determined by inspecting the level-response function, measured using the optimal ITD and ILD. Threshold was defined as the lowest average binaural level (average of the sound levels at both ears) that evoked at least one spike in response to each of five consecutive stimuli. Finally, ITD tuning was assessed three to seven times using a 20repetition stimulus series using the optimal ILD and an average binaural level $10 \mathrm{~dB}$ above threshold. Each ITD within a stimulus series was presented in a randomized, interleaved order with an interstimulus interval of $0.7-1 \mathrm{sec}$. Response magnitude was measured by subtracting the number of spikes in the $100 \mathrm{msec}$ before stimulus onset from the number of spikes in the $100 \mathrm{msec}$ after stimulus onset. Only sites that showed stable response properties $(<10 \%$ variation on maximum spike counts among three to seven consecutive ITD tuning curves) were used in pharmacological experiments.

Iontophoresis. The response properties described above were reassessed during the iontophoretic application of bicuculline methiodide (10 mM in $0.9 \%$ saline, adjusted to pH 3.0 with HCl; Sigma, St. Louis, MO).
The effective iontophoretic current level that resulted in a clear increase in responses typically ranged from 30 to $60 \mathrm{nA}$. At the majority of sites, response threshold remained unchanged during bicuculline application. At a few sites, however, the threshold decreased by up to $10 \mathrm{~dB}$ from the control level. For these sites, the sound level used for reassessing ITD tuning was adjusted accordingly to $10 \mathrm{~dB}$ above the threshold measured during bicuculline application. Once the response properties were stable and reassessment of the response properties was completed, bicuculline iontophoresis was halted, responses were allowed to recover, and ITD tuning was assessed again. Only sites that showed full recovery of control responses were used in data analysis.

To examine whether GABAergic inhibition differentially suppressed NMDA receptor-mediated responses, the effect of bicuculline application on ITD tuning at some ICX sites was examined before and during blockade of NMDA receptors with AP-5 (50 mM in $\mathrm{dH}_{2} \mathrm{O}$, adjusted to $\mathrm{pH} 7.4$ with $\mathrm{NaOH}$; Sigma). One of two protocols for drug application was chosen randomly for any given site. In one protocol, AP-5 was applied first. After obtaining stable responses, bicuculline was injected through a separate barrel. After stable ITD tuning was established during simultaneous application of the two drugs, AP-5 application was halted, and bicuculline application was continued. Finally, the site was allowed to recover from the effect of bicuculline application alone. In the other protocol, the order of the applied drugs was reversed: bicuculline was applied first, and AP-5 was added later. The results from using these two protocols were indistinguishable. Therefore, the data were combined for analysis.

Predicting normal ITD tuning. The experiments were conducted in the rostrolateral ICX, where in normal owls, neurons are tuned to frontal space (ITDs ranging from 0 to $20 \mu$ sec contralateral-ear leading). The ITD tuning of neurons in this region has been shown to shift reliably in response to juvenile prism experience (Brainard and Knudsen, 1993; Brainard and Knudsen, 1998). The value of ITD to which a site in the ICX will be tuned in a normal owl can be predicted $( \pm 10 \mu \mathrm{sec})$ by recording units along transects that pass through the representation of a given value of ITD both in the ICC and in the optic tectum: sites in the ICX that lie along these transects are tuned to this same value of ITD.

The ITD tuning that would have been observed normally at a site in the ICX of a prism-reared owl can be predicted in the same way. Prism experience does not alter the representation of ITD in the ICC (Brainard and Knudsen, 1993). In addition, it does not alter tectal visual receptive field locations, which can be used to predict normal ITD tuning. In this study, the transect ITD value was determined at the beginning of each experiment, in both normal and prism-reared owls, from the best ITD measured in the ICC and from the best ITD inferred from the visual receptive field location measured in the optic tectum. All ITD values are reported relative to the transect (predicted normal) ITD.

Data analyses. All ITD values were transformed into ITDs relative to the predicted normal ITD for each site. For data from prism-reared owls, ITDs in the adaptive direction were defined as positive, and ITDs in the nonadaptive direction were defined as negative. The data are reported as mean \pm SD of the mean. Error bars on Figures indicate mean \pm SEM. Unless noted, unpaired, two-tail Student's $t$ tests were used throughout the data analysis.

Normal ITDs were defined as the ITDs of $0 \pm 10 \mu \mathrm{sec}$ relative to the transect value for the site. Learned ITDs were the ITDs of $40 \pm 10 \mu \mathrm{sec}$ away from the transect value in the adaptive direction. These values of ITD were selected because in owls raised with $23^{\circ}$ prisms for long periods of time, the average shift in ITD tuning is $\sim 40 \mu \mathrm{sec}$. Responses of neurons to the normal ITDs and the learned ITDs were defined as normal responses and learned responses, respectively. Responses obtained during bicuculline application were defined as excitatory responses.

Shift metric indicates the strength of learned responses relative to normal responses at each site in prism-reared owls. It was defined as learned responses/(learned responses + normal responses). In calculating this metric for sites in normal owls, "learned" responses were defined as responses to ITDs displaced by $40 \pm 10 \mu \mathrm{sec}$ toward right-ear leading. In normal owls, the shift metric ranged from 0.02 to 0.41 (see Fig. $1 d$, open circles), reflecting a variation in tuning curve width. After $\sim 8$ weeks of prism experience, the shift metric ranged from 0.65 to 0.90 (see Fig. $1 d$, gray filled circles), indicating a large degree of elimination of normal responses and acquisition of learned responses.

Weighted average ITD was used to represent the value of ITD to which each site was tuned. It was calculated as follows: the sum of the products of ITD value and the corresponding response magnitude di- 
Figure 1. Experience-driven adjustment of ITD tuning in the ICX of prismwearing owls. $a$, Shift of ITD tuning recorded from three ICX sites in a single owl after different amounts of continuous prism experience: dashed-line curve, $10 \mathrm{~d}$ of experience; open circles, $30 \mathrm{~d}$ of experience; filled circles, $44 \mathrm{~d}$ of experience. Normalized responses are plotted relative to predicted normal best ITD for each site. Normal and learned ranges of ITD (defined in Materials and Methods) are indicated by gray bars labeled $N M L$ and $L N D$, respectively. $b$, Variation of ITD tuning shifts in the rostral ICX measured on different days in a single owl. ITD tuning shift was the difference between the weighted average ITD and the predicted normal ITD for each site. The shaded triangles indicate the sites for which tuning curves are plotted in $a$. Gray region indicates the range of weighted average ITDs relative to predicted normal observed in normal owls. $c$, Correlation of ITD tuning shifts with tuning for ILD (dorsoventral location in the ICX). Same data as plotted in $b$. In normal owls, the weighted average ITD did not change as the electrode was advanced from dorsal to ventral through the ICX (data not shown). $d$, Shift of weighted average ITD as a function of the shift metric (see

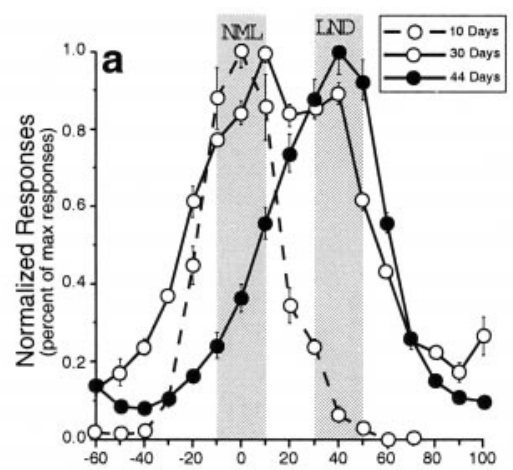

ITD (relative to predicted normal; $\mu$ s)
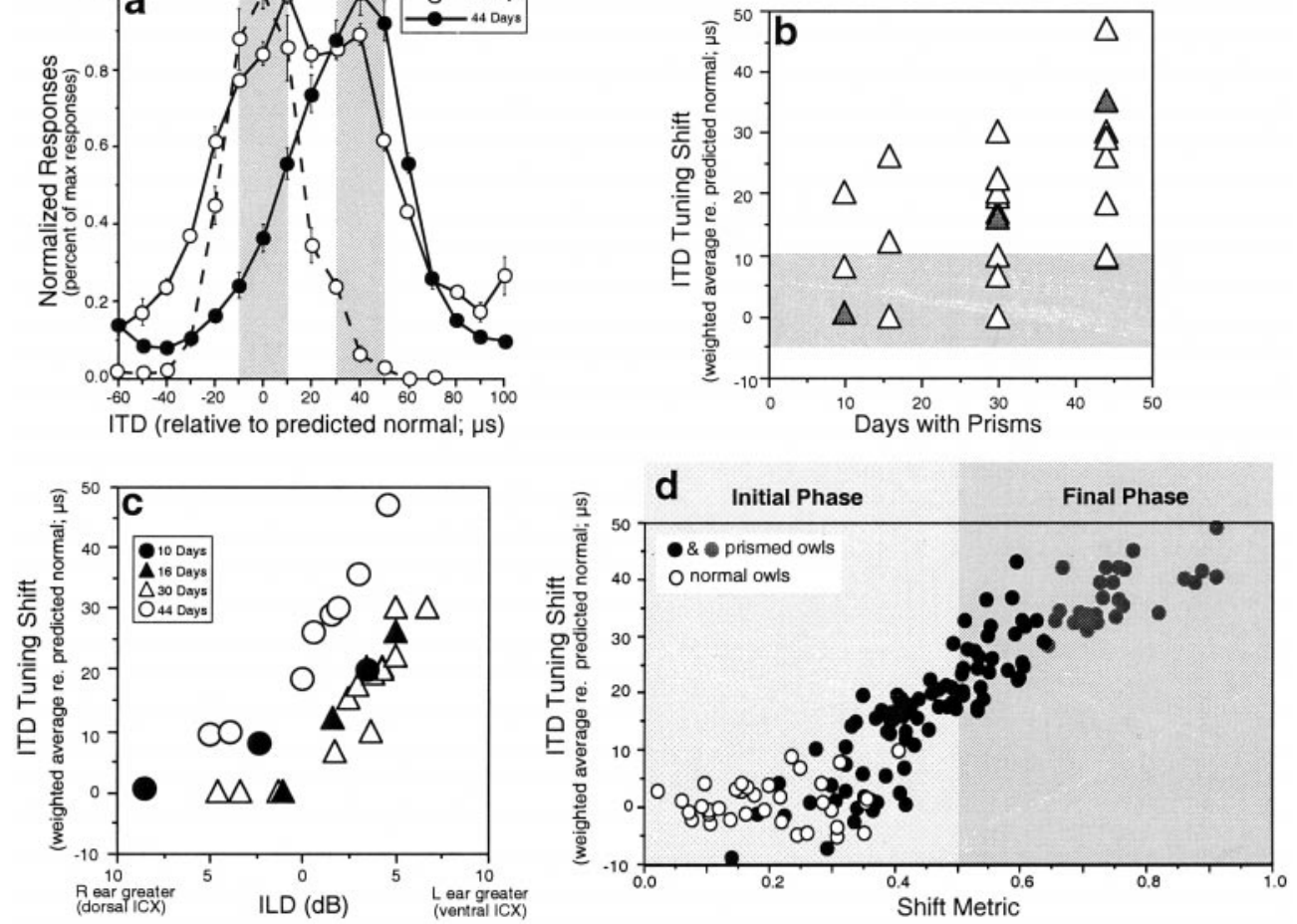

Materials and Methods). In normal owls (open circles), weighted average ITD was not correlated with shift metric (least-squares linear regression, $r^{2}=$ $0.01, p=0.57$ ). In prism-wearing owls ( filled circles), weighted average ITD was strongly correlated with shift metric (least-squares linear regression, $\left.r^{2}=0.91, p<0.0001\right)$. Gray filled circles represent the sites studied in a previous report (Zheng and Knudsen, 1999).

vided by the sum of all responses. Weighted average ITD was used instead of best ITD (the metric used in previous reports) because, during the dynamic phases of adjustment, many tuning curves exhibited highly asymmetrical shapes.

Tuning curve width was measured as the interpolated ITD ranges over which responses exceeded $40,45,50,55$, and $60 \%$ of the maximum excitatory response, respectively. The average of these values is reported as tuning curve width.

Shift of tuning curve flank induced by bicuculline application was measured separately for the right and left flanks of each tuning curve. It indicates the effect of GABAergic inhibition on each flank. It was computed by measuring the interpolated ITD values that evoked responses $40,45,50,55$, and $60 \%$ of the maximum excitatory response, respectively. The average of the differences in these ITD values measured with and without bicuculline was reported as the shift of the tuning curve flank.

Strength of inhibition was assessed separately for the right and left sides of each tuning curve. It conveyed the relative strength of inhibition on each side. It was computed by the percentage suppression of excitatory responses at the interpolated levels of $40,45,50,55$, and $60 \%$ of the maximal excitatory responses, respectively: (response with bicuculline control response)/response with bicuculline. The average of the percentage suppression at these excitatory response levels was used for assessing the strength of inhibition on the adaptive and nonadaptive flanks of the ITD tuning curve for each site.

\section{RESULTS}

\section{Time course of plasticity}

Experience with prisms that displaced the visual field horizontally by $23^{\circ}$ caused a gradual, adaptive shift in the map of ITD in the ICX of juvenile barn owls. We monitored the shift of the map in a region of the ICX where all units are normally tuned to frontal space and, therefore, to values of ITD near $0 \mu \mathrm{sec}$.

Examples of the changes in ITD tuning that occurred in this region of the map in a bird wearing prisms are shown in Figure 1a. Shortly (10 d) after prism experience began (dashed line curve), the ITD tuning curve was still symmetrical and centered near the predicted normal ITD, as in normal owls. With 20-30 d of prism experience (open circles), many sites in this same region of the ICX had acquired substantial responses (learned responses) to ITDs $40 \pm 10 \mu \mathrm{sec}$ away from normal in the adaptive direction. These sites still retained strong responses to ITDs near $0 \pm 10 \mu \mathrm{sec}$ (normal responses); hence their tuning curves were unusually broad. By $44 \mathrm{~d}$ of prism experience ( filled circles), many sites in this region of the ICX had lost responsiveness to ITDs near $0 \mu \mathrm{sec}$ and were selective for ITDs that were shifted 25-50 $\mu \mathrm{sec}$ away from normal in the adaptive direction, resulting in tuning curves as narrow as those in normal owls.

The experience-induced shifts in ITD tuning were not uniform across the map, even within this restricted region of the ICX. Figure $1 b$ shows the distributions of ITD tunings measured during sequential experiments in a single owl. After $10 \mathrm{~d}$ of prism experience, a site was found with ITD tuning that was shifted in the adaptive direction (Fig. $1 b$ ). With additional experience, the prevalence of such sites increased. The magnitude of the shift of ITD tuning that was observed on any given day covaried with the location of the recording site within the ICX (Fig. 1c). At dorsally located sites, tuned to right-ear greater ILDs (corresponding to auditory spatial receptive fields located above the horizon), ITD tuning remained relatively unshifted. However, at more ventrally located sites, tuned to left-ear greater ILDs (corresponding to receptive fields below the horizon), ITD tuning had shifted substantially. This pattern was observed in each of the prismreared owls in this study. Thus, consistent with studies on the effect of prism experience on ITD tuning of neurons in the optic tectum (Brainard and Knudsen, 1995), the timing and extent of 


\section{Normal Owl}
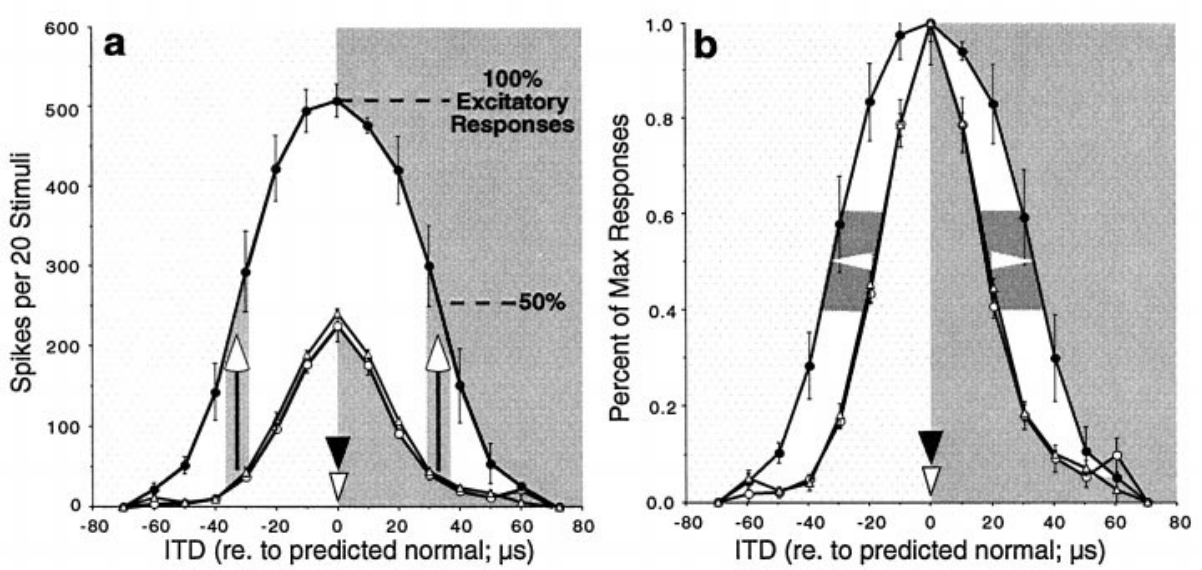

Prismed Owl
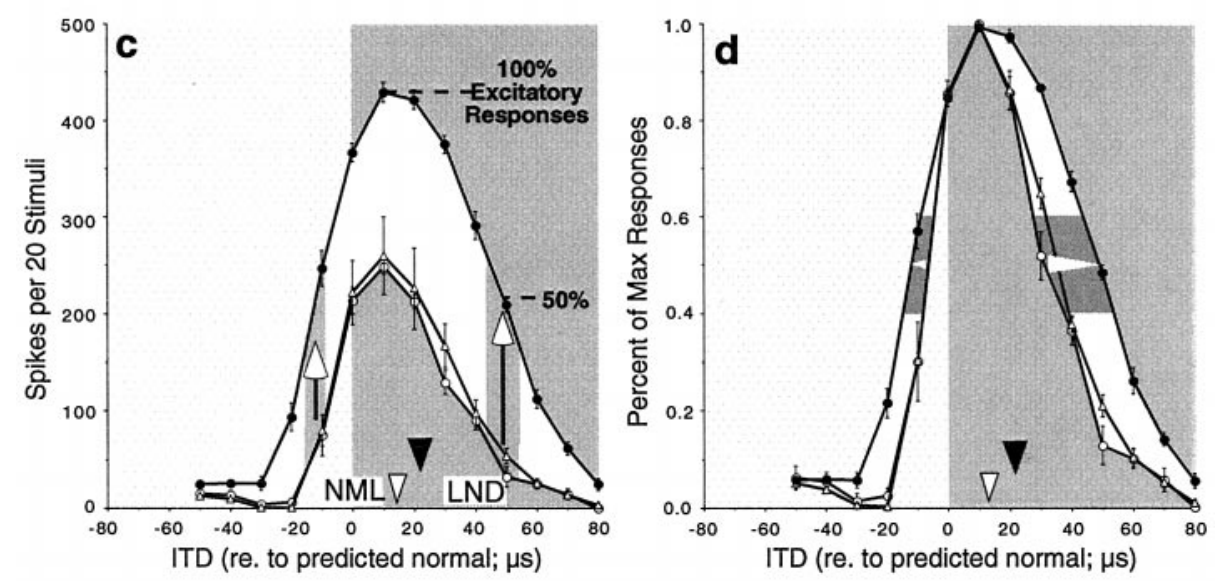

Figure 2. Effects of blocking $\mathrm{GABA}_{\mathrm{A}}$-mediated inhibition on ITD tuning in the ICX. $a$, Representative ITD tuning curves measured before (open circles), during ( filled circles), and after (open triangles) bicuculline application at a single site in a normal owl. Each data point represents the number of spikes evoked by 20 stimulus repetitions averaged across five series of stimuli. GABAergic inhibition caused a symmetrical decrease in responses on the two flanks of the tuning curve. The weighted average ITD before (open arrowhead) and during (filled arrowhead) bicuculline application remained unchanged. Open arrows represent the bicuculline-induced increase in the neuronal responses on the flanks of the tuning curve measured at $40-60 \%$ of the maximum excitatory responses, as indicated by the gray vertical bars. $b$, Normalized tuning curves based on the data plotted in a. Open horizontal arrowheads indicate the shift of the flanks of the tuning curve (see Materials and Methods). $c$, Representative ITD tuning curves measured before (open circles), during ( filled circles), and after (open triangles) bicuculline application at a single site that was in the initial phase of adjustment in a prism-wearing owl. The data are plotted as in $a$. NML and $L N D$ indicate the predicted normal best and the learned ITD range (see Materials and Methods), respectively. The average percentage of excitatory responses suppressed by GABAergic inhibition (see Materials and Methods) was significantly greater on the adaptive flank than on the nonadaptive flank $(79 \pm 4.5$ vs $68 \pm 3.7 \%$; $p<$ 0.01). The weighted average ITD (downward arrowheads) shifted by $8 \mu \mathrm{sec}$ in the adaptive direction during bicuculline application. $d$, Normalized tuning curves based on data plotted in $c$. The shift of the tuning curve flank (open horizontal arrowheads) was significantly greater on the adaptive flank than on the nonadaptive flank $(16.6 \pm 0.9$ vs $5.8 \pm 1.5 \mu \mathrm{sec}$; $p<0.01)$. shifts varied across different portions of the auditory space map in the ICX.

\section{Phases of adjustment}

As described above, different portions of the ITD map could be at different stages of adjustment on any given day. To quantify the amount of adjustment that had occurred at a particular site, we derived a shift metric, defined as the magnitude of learned responses divided by the sum of learned and normal responses (see Materials and Methods).

In normal owls, unit responses to ITDs $40 \pm 10 \mu \mathrm{sec}$ away from the predicted normal value were, on average, $25 \%$ as strong as responses to the predicted normal ITDs $\pm 10 \mu \mathrm{sec}$, corresponding to an average shift metric of 0.20 . Shift metrics in normal owls ranged from 0.02 to 0.41 (Fig. $1 d$, open circles), reflecting variation in tuning curve width. In prism-wearing owls, the shift metric ranged from 0.15 to 0.90 and, as expected, correlated with the shift in ITD tuning measured at each site (Fig. 1d, filled circles).

The shift metric was used to define two phases in the adjustment process (see Discussion): initial phase and final phase. Sites at which the shift metric was $<0.50$ were classified as being in the initial phase of adjustment. At these sites, normal responses were stronger than learned responses. Sites at which the shift metric was $\geq 0.50$ were classified as being in the final phase of adjustment. At these sites, learned responses were equal to or stronger than normal responses. In owls with $>30 \mathrm{~d}$ of prism experience, individual sites in the ICX could be in either of these phases of adjustment, depending on their location in the map (Fig. 1c).

\section{Effects of bicuculline iontophoresis on ITD tuning}

As reported earlier (Fujita and Konishi, 1991; Zheng and Knudsen, 1999), bicuculline iontophoresis in the rostraI ICX (see Materials and Methods) of normal owls had a symmetrical effect on ITD tuning curves. This effect is shown for a single site in Figure 2, $a$ and $b$. Bicuculline iontophoresis caused responses on the two flanks of the tuning curve (see Materials and Methods) to increase equally (Fig. $2 a$, arrows) and the two flanks to shift outward by similar amounts (Fig. $2 b$, arrowheads). As a result, the weighted average ITD remained unchanged before and during bicuculline application (Fig. 2a,b, downward arrowheads).

Unlike in normal owls, bicuculline iontophoresis in the rostraI ICX of prism-wearing owls that were in the initial phase of adaptive adjustment (shift metric $<0.50 ; n=64$ ) caused the weighted average ITD to shift in the adaptive direction. An example of this effect at a representative site is shown in Figure $2, c$ and $d$. Before bicuculline application, the weighted average ITD at this site was $13 \mu \mathrm{sec}$ in the adaptive direction relative to predicted normal (open arrowhead). During bicuculline application, the weighted average shifted in the adaptive direction to 21 

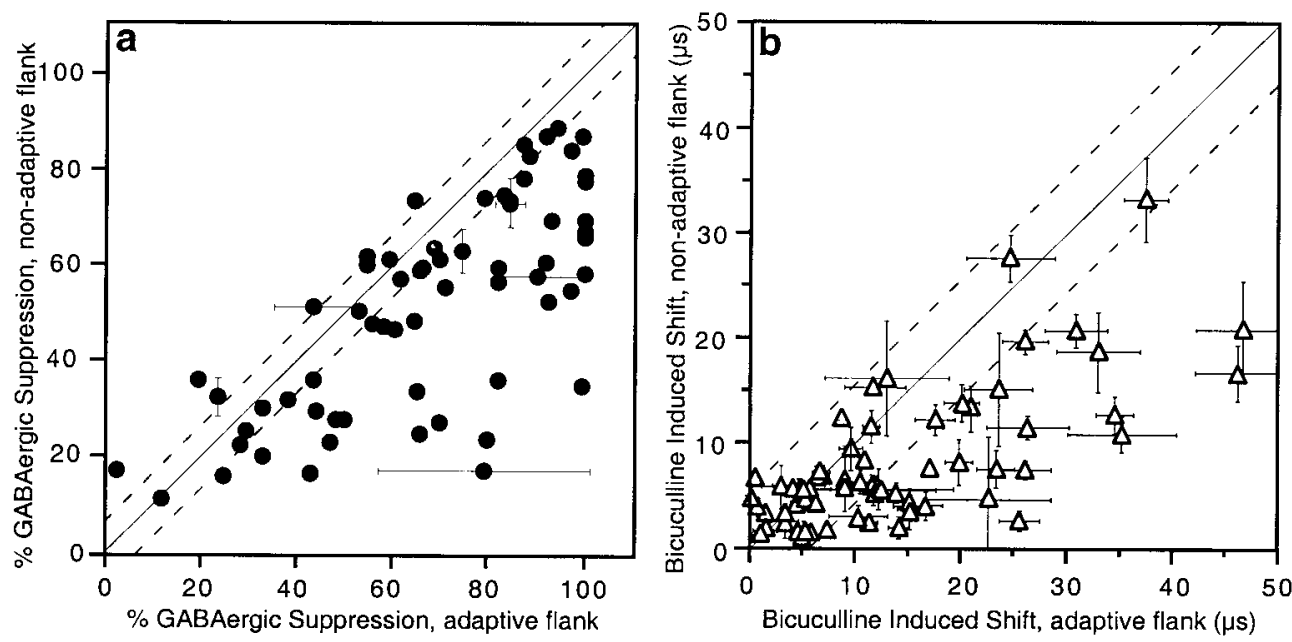

Figure 3. Summary of asymmetrical effects of inhibition on ITD tuning in the ICX during the initial phase of adaptive adjustment. Diagonal solid lines indicate equal values; dashed lines indicate the mean \pm 2 SD for the data from normal owls. $a$, Comparison of the percentage suppression of the excitatory responses on the two flanks at the level of $40-60 \%$ of the maximal excitatory responses. The average difference in the percentage suppression of the excitatory responses between the two flanks across the population in prism-wearing owls was significantly greater than that in normal owls $(19.7 \pm 2.1$ vs $0.61 \pm 5.9 \%$; Mann-Whitney $U$ test, $p<0.0001) . b$, Comparison between the bicuculline-induced shifts in the flanks of each tuning curve. The average difference in the shifts of the two flanks across the population in prism-wearing owls was significantly greater than that in normal owls $(5.5 \pm 7.6 \mathrm{vs} 0.76 \pm$ $4.2 \mu \mathrm{sec}$; Mann-Whitney $U$ test, $p<0.0001)$.

$\mu \sec$ ( filled arrowhead). After bicuculline iontophoresis was discontinued, the weighted average shifted back to $13 \mu$ sec.

The shift in the weighted average ITD that resulted from blocking inhibition at this site was caused by differential suppression of excitatory responses to ITDs on the adaptive flank of the tuning curve. The average percentage suppression of excitatory responses (measured at the level of $40-60 \%$ of the maximum response) was significantly greater on the adaptive flank than on the nonadaptive flank $(p<0.01)$ (Fig. $2 c)$. In addition, the shift of the tuning curve flank was significantly greater on the adaptive flank than on the nonadaptive flank ( $p<0.01)$ (Fig. 2d). Bicuculline application had a similarly asymmetrical effect on ITD tuning at the majority ( 41 of 64 ) of the sites that were in the initial phase of adjustment. At the remaining sites, bicuculline application had symmetrical effects on ITD tuning, similar to those observed in normal owls. The ITD tuning curves of these sites obtained before bicuculline application also resembled those in normal owls: symmetric tuning curves with weighted average ITDs centered on the predicted normal best ITDs. It is likely, therefore, that no adjustment of ITD tuning had occurred at these sites.

Figure $3 a$ compares GABAergic suppression of excitatory responses on the adaptive and nonadaptive flanks of the tuning curve for each ICX site $(n=64)$. For the majority (64\%) of the sites, the suppression of excitatory responses (strength of inhibition; see Materials and Methods) was significantly greater on the adaptive flank than on the nonadaptive flank $(p<0.05)$. Figure $3 b$ compares the shifts of the two flanks of the tuning curve for each site. Approximately $50 \%$ of the points lie outside of the normal distribution (dashed lines; see Fig. 3 legend), always in the adaptive direction.

The differential GABAergic suppression of learned responses indicates that the strength of inhibition was greater on the adaptive side than on the nonadaptive side of the tuning curves. This differentially strong inhibition on the adaptive flank suppressed responses to newly functional, adaptive excitatory inputs. Thus, blocking inhibition in the initial phase of adjustment revealed that a greater amount of adaptive adjustment in excitatory input had occurred than was apparent with inhibition present.

\section{Effects of AP-5 and bicuculline iontophoresis on ITD tuning}

We also examined the asymmetrical effects of bicuculline at a subset of the ICX sites $(n=47)$ that were in the initial phase of adjustment while NMDA receptors were blocked by iontophoretic application of AP-5 (see Materials and Methods). As was reported by Feldman et al. (Feldman et al., 1996; Feldman and Knudsen, 1998b), blocking NMDA receptors with AP-5 decreased learned responses as much as or more than normal responses. Regardless of the effect of blocking NMDA receptors on ITD tuning, however, bicuculline iontophoresis had the same asymmetrical effect on ITD tuning as that described above.

Figure 4 illustrates the results of a series of sequential pharmacological experiments performed at a site where learned responses were differentially mediated by NMDA receptors. First, AP-5 was applied at this site. Application of AP-5 differentially decreased learned responses (Fig. $4 a$ ), causing the ITD tuning curve to shift in the nonadaptive direction (Fig. 4b). Next, bicuculline was injected through a separate barrel of the multibarrel microelectrode while AP-5 application was continued. Application of bicuculline in the presence of AP-5 had an asymmetrical effect on the ITD tuning (Fig. $4 c$ ), causing the ITD tuning curve to shift in the adaptive direction (Fig. 4d). Finally, AP-5 application was discontinued while bicuculline iontophoresis was continued. Not surprisingly, bicuculline application alone had a differentially strong effect on the adaptive flank of the tuning curve (Fig. 4e,f).

Figure 5 illustrates the results of a series of sequential pharmacological experiments performed at a site where learned responses were not differentially mediated by NMDA receptors. First, AP-5 was applied at this site. Application of AP-5 decreased learned and normal responses similarly (Fig. $5 a$ ), causing the ITD tuning curve to narrow similarly on the adaptive and nonadaptive flanks (Fig. $5 b$ ). Next, bicuculline was injected 


\section{Blocking NMDA Receptors with AP-5}
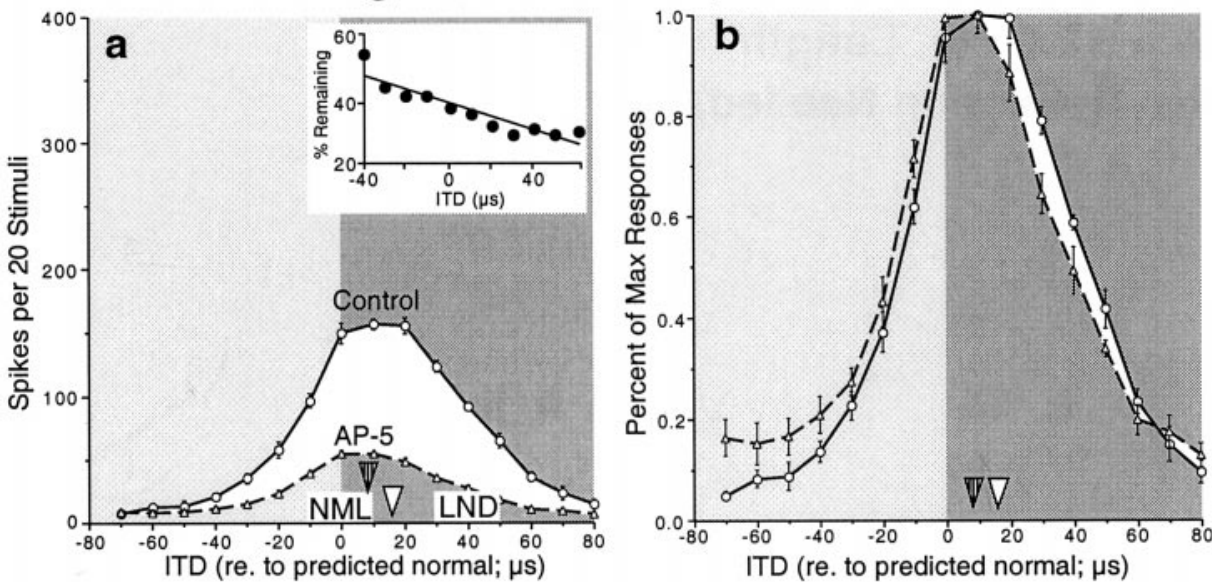

Blocking NMDA and GABAa Receptors
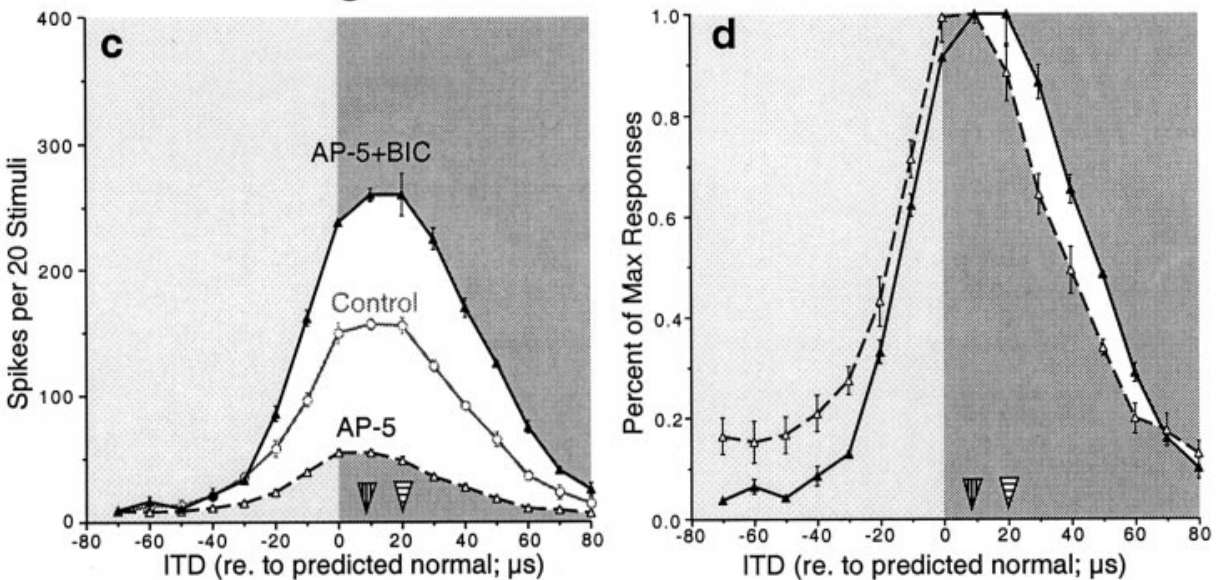

Blocking GABAa Receptors with Bicuculline
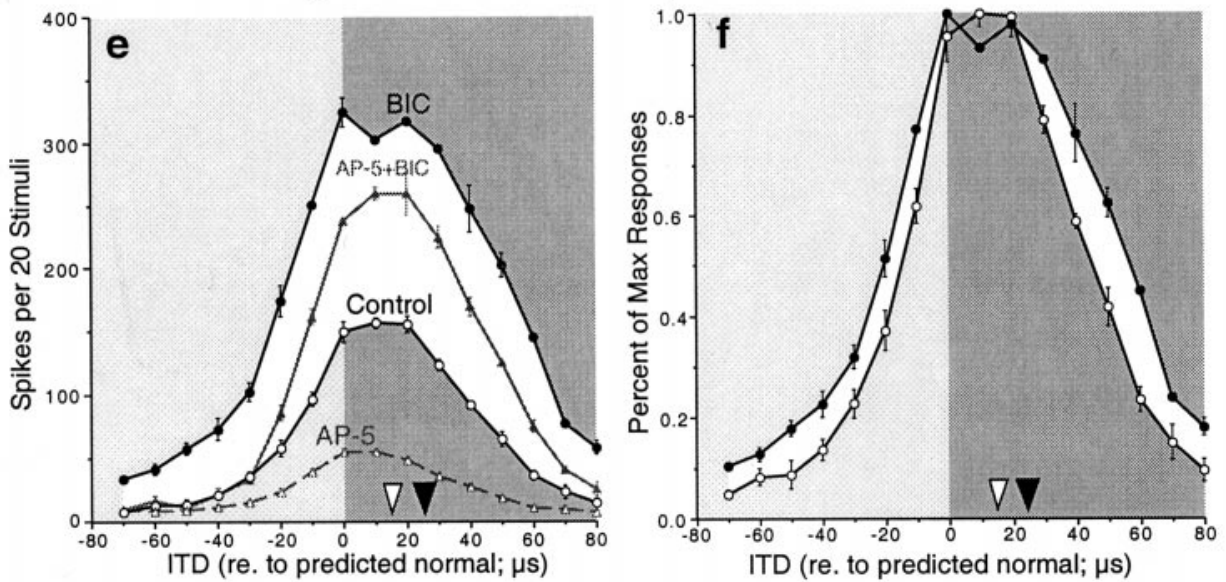

Figure 4. Asymmetrical effect of bicuculline $(B I C)$ on ITD tuning is independent of NMDA receptor currents at an ICX site at which the newly learned responses are differentially mediated by NMDA receptors. All tuning curves are plotted as in Figure 2: left panels, tuning curves plotted using number of spikes; right panels, normalized tuning curves. $a, b$, Application of AP-5 alone differentially suppressed the learned responses and shifted the tuning curve in the nonadaptive direction. The weighted average ITD before (open arrowhead) and during (vertically striped arrowhead) AP-5 application shifted $8 \mu \mathrm{sec}$ toward the nonadaptive direction. $a$, Inset, Percentage control response remaining during AP-5 application as a function of ITD relative to predicted normal. This analysis was restricted to ITD values that evoked at least $10 \%$ of the maximal control responses. Line, Leastsquares linear regression $\left(r^{2}=0.840, p<\right.$ $0.0001)$. A non-zero slope $(p<0.05)$ indicates a significant difference in response blockade by AP-5 across the range of ITDs examined. $c, d$, Application of bicuculline during blockade of NMDA receptors by AP-5 induced a greater increase in responses on the adaptive than on the nonadaptive side of the tuning curve $(104.7 \pm 39.3$ vs $30.3 \pm 27.9$ spikes/20 stimuli; $p<0.01)$ and shifted the tuning curve to the adaptive direction. The weighted average ITD during AP-5 application (vertically striped arrowhead) and during simultaneous application of AP-5 and bicuculline (horizontally striped arrowhead) shifted 12 $\mu \mathrm{sec}$ toward the adaptive direction. $e, f$, Application of bicuculline alone induced a greater increase in responses on the adaptive than on the nonadaptive side of the tuning curve $(134.2 \pm 23.5$ vs $83.0 \pm 41.1$ spikes $/ 20$ stimuli; $p<0.05)$ and shifted the tuning curve flank on the adaptive side farther than on the nonadaptive side $(12.6 \pm 0.3$ vs $6.1 \pm 0.9 \mu \mathrm{sec}$; $p<0.01)$. The weighted average ITD before (open arrowhead) and during (filled arrowhead) bicuculline application shifted $10 \mu \mathrm{sec}$ toward the adaptive direction. through a separate barrel of the multibarrel microelectrode while AP-5 application was continued. Application of bicuculline in the presence of AP-5 had an asymmetrical effect on the ITD tuning (Fig. $5 c$ ): it shifted the adaptive flank farther than it shifted the nonadaptive flank (Fig. $5 d$ ). Finally, AP-5 application was discontinued while bicuculline iontophoresis was continued. As expected, bicuculline application alone had a differentially strong effect on the adaptive flank of the tuning curve (Fig. $5 e, f$ ).
The persistence of the asymmetrical effect of blocking inhibition on ITD tuning in the presence or absence of NMDAmediated neural transmission is summarized in Figure 6 for all sites that were in the initial phase of adjustment. The tendency for bicuculline application to induce a larger shift of the adaptive flank over the nonadaptive flank was evident, both with and without AP-5 application (Fig. 6b, triangles and crosses, respectively). These asymmetrical effects of bicuculline were not differ- 


\section{Blocking NMDA Receptors with AP-5}

Figure 5. Asymmetrical effect of bicuculline on ITD tuning is independent of NMDA receptor currents at an ICX site at which the newly learned responses are not differentially mediated by NMDA receptors. All tuning curves are plotted as in Figure 2: left panels, tuning curves plotted using number of spikes; right panels, normalized tuning curves. $a, b$, Application of AP-5 alone suppressed the learned and normal responses similarly and narrowed the tuning curve symmetrically. The weighted average ITD before (open arrowhead) and during (vertically striped arrowhead) AP-5 application remained unchanged. $a$, Inset, Percentage control response remaining during AP-5 application as a function of ITD relative to predicted normal. This analysis was restricted to ITD values that evoked at least $10 \%$ of the maximal control responses. Line, Least-squares linear regression $\left(r^{2}=\right.$ $0.017, p=0.72)$. A non-zero slope $(p<0.05)$ indicates a significant difference in response blockade by AP-5 across the range of ITDs examined. $c, d$, Application of bicuculline during blockade of NMDA receptors by AP-5 induced a greater increase in responses on the adaptive than on the nonadaptive side of the tuning curve $(113.9 \pm 29.2$ vs $36.1 \pm 28.7$ spikes/20 stimuli; $p<0.01)$ and differentially shifted the tuning curve flank on the adaptive side. The weighted average ITD during AP-5 application (vertically striped arrowhead) and during simultaneous application of AP-5 and bicuculline (horizontally striped arrowhead) shifted $8 \mu \mathrm{sec}$ toward the adaptive direction. $e, f$, Application of bicuculline alone induced a greater increase in responses on the adaptive than on the nonadaptive side of the tuning curve $(152.8 \pm 16.6$ vs $76.9 \pm 32.1$ spikes $/ 20$ stimuli; $p<0.01)$ and shifted the tuning curve flank on the adaptive side farther than on the nonadaptive side $(16.3 \pm 2.3$ vs $3.8 \pm 0.9 \mu$ sec; $p<0.01)$. The weighted average ITD before (open arrowhead) and during ( filled arrowhead) bicuculline application shifted $9 \mu \mathrm{sec}$ toward the adaptive direction.
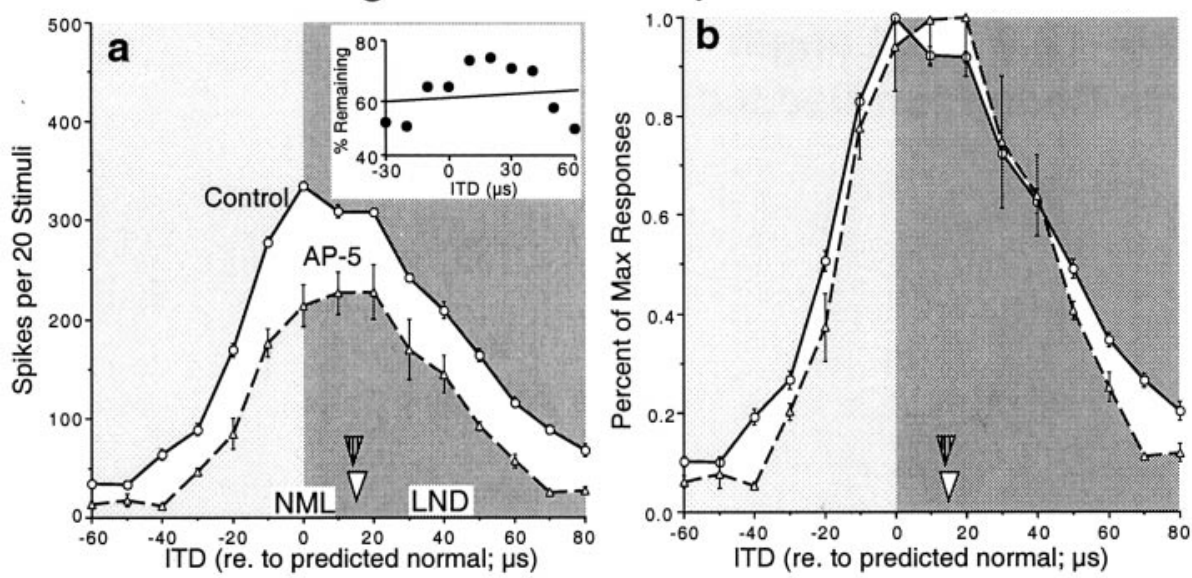

\section{Blocking NMDA and GABAa Receptors}
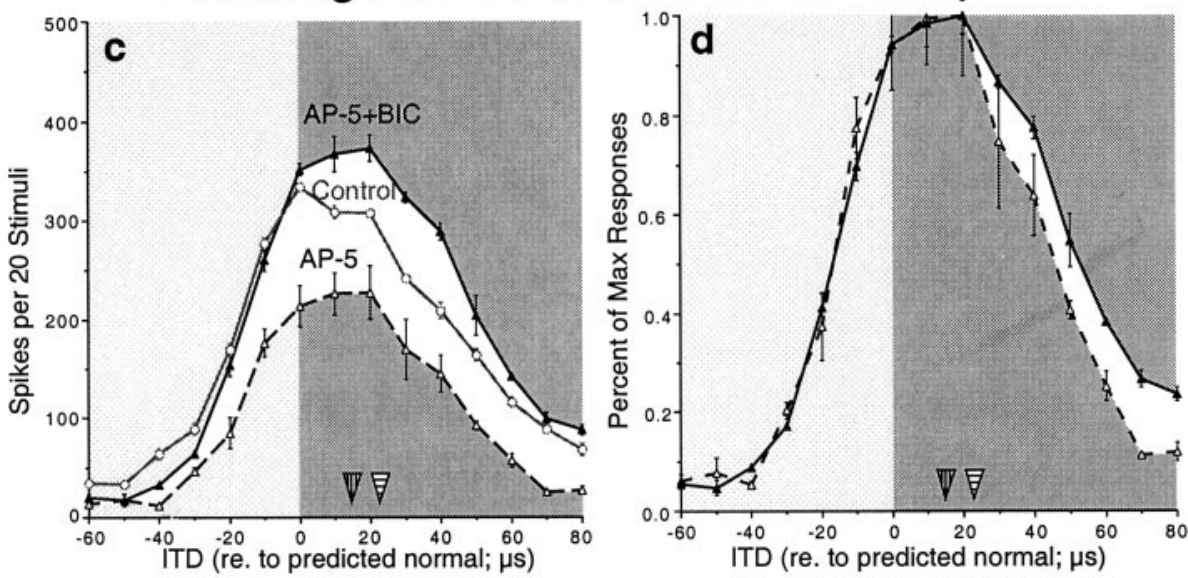

\section{Blocking GABAa Receptors with Bicuculline}
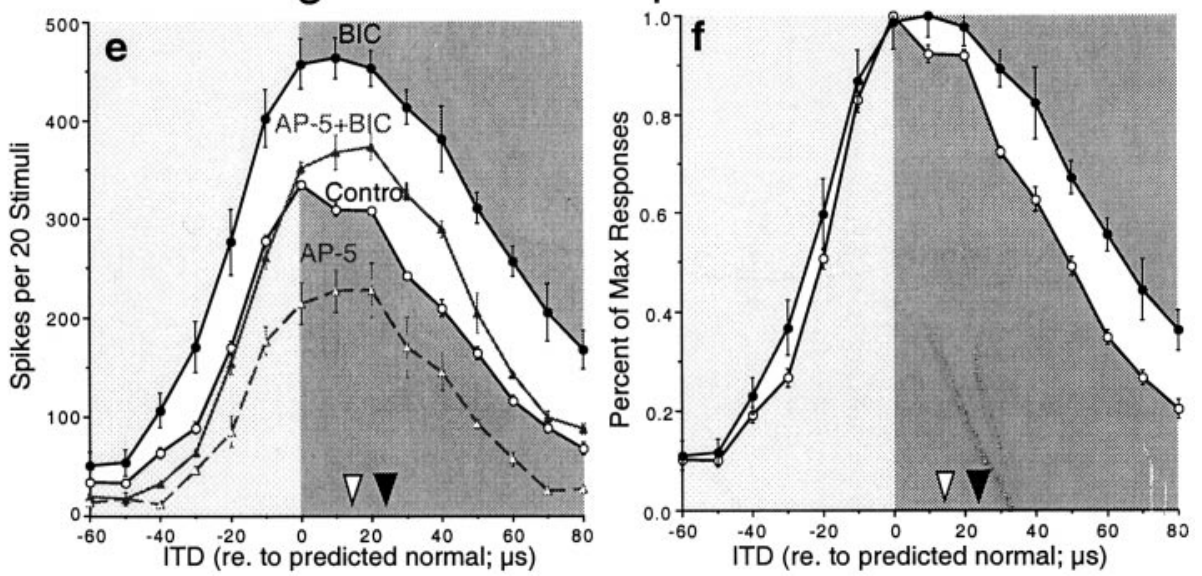

ent across the population with or without AP-5 (Mann-Whitney $U$ test, $p>0.1$ ). Thus, independent of the activity of NMDA receptors, responses to the newly functional, excitatory inputs were differentially suppressed by GABAergic inhibition.

\section{DISCUSSION}

We found that initially in the adaptive adjustment of the auditory space map in the ICX of barn owls, responses of neurons to newly acquired, functional excitatory inputs are differentially sup- pressed by GABAergic inhibition. In theory, this effect of inhibition could be accounted for by the voltage dependence of NMDA receptor currents (Nowak et al., 1984; Feldman and Knudsen, 1998a; Isaac et al., 1999; Nicoll and Malenka 1999), which are known to contribute importantly at the synapses that mediate the newly learned responses (Feldman et al., 1996; Feldman and Knudsen, 1998b). However, the differential effect of inhibition on these learned responses persists even when NMDA receptors are blocked by AP-5 (Figs. 4-6). Therefore, the effect of GABAergic 


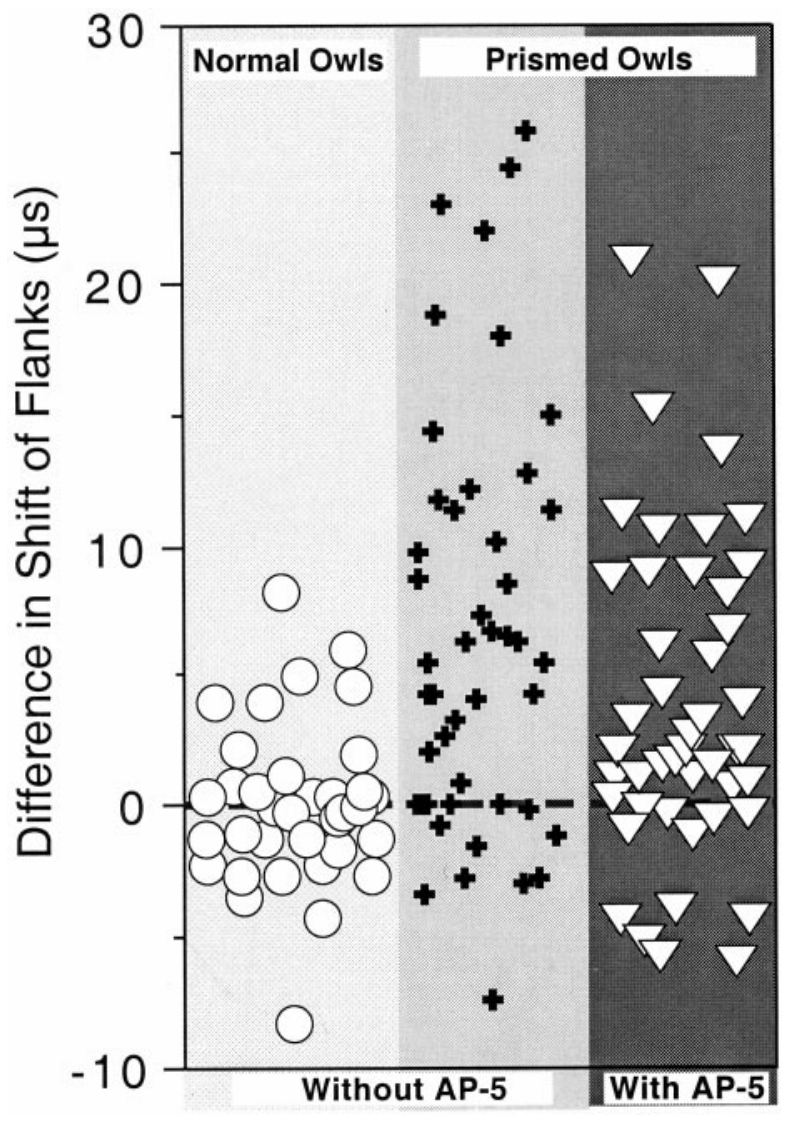

Figure 6. Summary of asymmetrical effects of bicuculline application on ITD tuning with and without AP-5 application at all ICX sites $(n=47)$ tested with sequential AP-5/bicuculline application protocols. Open circles are data obtained from normal owls; crosses and open triangles are data from prism-wearing owls obtained without and with AP-5 application, respectively. Each data point represents the difference in bicucullineinduced shifts of the adaptive and nonadaptive flanks of ITD tuning curves. Positive values indicate a larger shift on the adaptive than on the nonadaptive flank.

inhibition is independent of the kind of glutamate receptor that mediates the adaptive excitatory input.

\section{Temporal dynamics and spatial variability of plasticity in the auditory space map}

The present study documents the continuous shift in ITD tuning in the ICX that occurs during the adjustment process. The time course of the shift in ITD tuning is very similar to that observed previously in the optic tectum using extensive acute and chronic recordings in prism-reared owls (Brainard and Knudsen, 1995). A general trend is apparent: the longer the prism experience, the larger the region of the map that is affected and the greater the shift in the affected portion of the map (Fig. 1). By 8 weeks of experience, the ITD map has stabilized on a new abnormal pattern that reflects the optical displacement of the visual field: regions of the map representing the optically displaced center of gaze are fully shifted, whereas those representing the periphery, which is obstructed by the spectacle frames, are normal or only slightly shifted (Brainard and Knudsen, 1993; Brainard and Knudsen, 1998).

The present study shows further that the rate of ITD tuning shift measured on a given day can vary across the map, even within the portion of the map representing the region of space that is displaced uniformly by the prisms (Fig. 1b,c). Sites in the dorsal portion of the ICX tended to have smaller adaptive shifts than sites in the ventral portion. This systematic, dorsal-ventral variation in ITD tuning shift was not caused by an incapacity of dorsal sites to shift ITD tuning, because these sites can show full shifts in ITD tuning after a long period of prism exposure (data not shown) (Brainard and Knudsen, 1993; Brainard and Knudsen, 1995). We believe that the difference in the amount of ITD tuning shift between the dorsal and ventral ICX sites reflects a large difference in the owl's experience with stimuli above or below the visual axes, respectively: Particularly in a flight room, audiovisual stimuli rarely occur above the owl's line of sight, but frequently occur in or below it. Previous research has shown that auditory map adjustment requires rich experience (Brainard and Knudsen, 1998). Thus, we hypothesize that sites in the dorsal ICX exhibited less of an ITD tuning shift than those in the ventral ICX, because they were shifting at a slower rate because of inferior experience.

In the present study, we examined the pharmacology of sites in the ICX that showed little shift in ITD tuning, although the owls may have worn prisms for many weeks. We assume that although such sites were slow in shifting ITD tuning for the reasons discussed above, they were nevertheless in the process of altering their ITD tuning. Therefore, sites with shift metric $<0.50$ are classified as in the initial phase of ITD tuning shift, while sites with shift metric $\geq 0.50$ are classified as in the final phase of ITD tuning shift.

\section{Possible mechanisms}

During the initial phase of map plasticity, the effect of GABAergic inhibition on ITD tuning is ITD dependent: neuronal responses on the adaptive side of ITD tuning curves are suppressed more than those on the nonadaptive side. To have this ITDdependent effect, the underlying mechanism must involve changes in connections that convey ITD-specific information. In an ICX that is in the process of acquiring a new representation of ITD, feedback signals that originate in or beyond the ICX encode both the normal and the learned ITDs and therefore are not ITD specific. In contrast, feedforward signals to the ICX remain ITD specific. Therefore, the differential GABAergic inhibition of the excitatory responses to learned ITDs must result from changes in feedforward connections to neurons in the ICX.

Candidate, feedforward connections in the ICX include both excitatory inputs to ICX neurons, which must change to cause adaptive adjustment in the space map, and inhibitory inputs, which might change. GABAergic, feedforward lateral inhibition to ICX neurons has been shown to powerfully suppress responses to inappropriate ITDs in frequency-specific channels (Mori, 1997). This same inhibition could also contribute to the GABAergic sharpening of ITD tuning that occurs in this nucleus (Fujita and Konishi, 1991; Albeck, 1997).

A specific increase in the strength of this feedforward inhibition from learned ITD channels could account for the differential inhibition of responses to learned inputs in the ICX. The increase can be caused by an increase in the strength of feedforward excitatory drive to inhibitory neurons. If the inhibitory neurons are exclusively feedforward, the increase could also occur because of an increase in the strength of these inhibitory connections themselves. According to this hypothesis, this increase in inhibition would accompany, and selectively suppress, the adaptive changes in excitatory input from these same channels. Such a change in the pattern of feedforward inhibition would tend to preserve the established normal auditory space map. The value of 
Figure 7. Changing effect of bicuculline application on the ITD tuning over the course of auditory space map plasticity. Each data point represents the difference in bicuculline-induced shifts of flanks between the adaptive and the nonadaptive sides of ITD tuning curves measured at each single ICX site $(a)$ or the difference in bicuculline-induced changes in the weighted average at each single ICX site $(b)$. Black symbols represent new sites collected in this study. Open symbols were data obtained from normal owls. Gray symbols represent sites that were reported previously (Zheng and Knudsen, 1999).
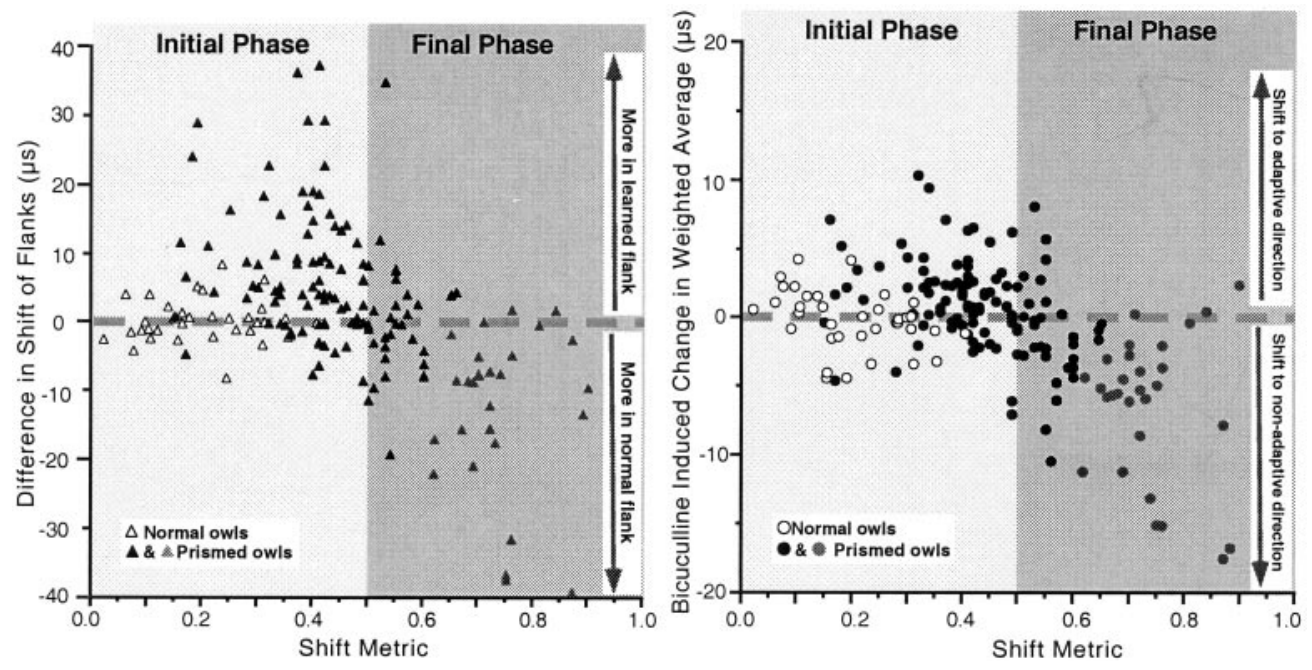

such a change is not obvious in the context of adaptation, however, because it would directly undermine the adaptive changes in the pattern of excitation that occur simultaneously.

Alternatively, the pattern of feedforward inhibition does not have to change to exert a differentially strong suppression of responses to newly learned inputs. Instead, the asymmetrical effect of inhibition could be caused by changes in feedforward connections to excitatory circuitry that are not accompanied by changes in feedforward connections to inhibitory circuitry. According to this second hypothesis, the pattern of feedforward inhibition remains strong and unchanged, whereas excitatory inputs to ICX neurons undergo rapid adaptive change. Without changes in the pattern of feedforward inhibition, responses to the new excitatory inputs would be suppressed by this preexisting, highly effective inhibition that normally serves to sharpen tuning curves and eliminate responses to inappropriate inputs (Fujita and Konishi, 1991; Mori, 1997). This hypothesis requires only that in response to experiential influences, the pattern of feedforward inhibition adjusts more slowly than does the pattern of feedforward excitation to ICX neurons.

Eventually, as adjustment proceeds into the final phase, the pattern of feedforward inhibition indeed adjusts and exerts an entirely different effect on the auditory space map (Zheng and Knudsen, 1999). The changing effect of inhibition on the auditory space map is summarized in Figure 7. In the early stages, inhibition differentially suppresses responses to newly learned inputs. In the late stages, inhibition differentially suppresses responses to normal, inappropriate inputs. The effect of inhibition during the final phase of auditory map plasticity is also ITD dependent and therefore must be caused by plastic changes in feedforward connections. In this case, the strength of inhibition associated with the normal, nonadaptive ITD channel increases selectively. This increase helps to eliminate responses to normal ITDs, enabling ITD tuning curves to shift fully so that they are centered on the new, visually instructed values of ITD (Fig. $1 a$, filled circles).

\section{Implications for plasticity}

During the initial phase of adaptive map adjustment, a substantial amount of plasticity in excitatory input that has taken place is not expressed in the spike activity of ICX neurons because of strong GABAergic inhibition. In networks that rely on Hebbian mechanisms to regulate synaptic strength, such as the representation of ocular dominance in the visual cortex (Kirkwood and Bear, 1994;
Katz and Shatz, 1996; Bear and Rittenhouse, 1999; Hata et al., 1999) or the representation of the body surface in the somatosensory cortex (Schlaggar et al., 1993; O'Leary et al., 1994), this differential inhibition of neuronal responses to new inputs would cause these new connections to weaken and would prevent adaptive change in the map. Indeed, the maturation of inhibitory circuitry has been reported to be slower than the maturation of the excitatory circuitry in these networks (Blue and Parnevelas, 1983; Komatsu, 1983; Luhmann and Prince, 1991; Micheva and Beaulieu, 1995, 1997; Gao et al., 1999, 2000) and has been linked to the closure of their sensitive periods (Kirkwood et al., 1995; Huang et al., 1999; Fagiolini and Hensch, 2000). Clearly, the interaction between inhibition and newly acquired excitatory inputs must be taken into account when proposing mechanisms of functional plasticity.

The plasticity of the auditory space map that results from prism experience is fundamentally different, however, from the plasticity of the visual and somatosensory maps mentioned above: it is driven not by self-organizational principles but, instead, by instruction from an outside network (Knudsen, 1994; Hyde and Knudsen, 2000). In this case, the barrier to plasticity exerted by inhibition (Kirkwood et al., 1995; Huang et al., 1999; Fagiolini and Hensch, 2000) is overcome by the influence of the instructive signal (Knudsen, 1994; Hyde and Knudsen, 2000). This occurs although inhibition is strong and apparently adult-like at the age of prism exposure (our unpublished data). One possibility is that instruction is accomplished by a presynaptic, non-Hebbian mechanism (Castillo et al., 1994; Urban and Barrionuevo, 1996; Schacher et al., 1997; Maccaferri et al., 1998). Strengthening of presynaptic excitatory inputs, independent of postsynaptic activity, could be a strategy used to escape the antagonistic influence of postsynaptic inhibition on Hebbian plasticity, thereby allowing the acquisition of entirely new, functional representations even in fully mature networks.

\section{REFERENCES}

Albeck Y (1997) Inhibition sensitive to interaural time difference in the barn owl's inferior colliculus. Hear Res 109:102-108.

Bear MF, Rittenhouse CD (1999) Molecular basis for induction of ocular dominance plasticity. J Neurobiol 41:83-91.

Blue ME, Parnevelas PJ (1983) The formation and maturation of synapses in the visual cortex of the rat. II. Quantitative analysis. J Neurocytol 12:697-712.

Brainard M, Knudsen E (1998) Sensitive periods for visual calibration of 
the auditory space map in the barn owl optic tectum. J Neurosci 18:3929-3942.

Brainard MS, Knudsen EI (1993) Experience-dependent plasticity in the inferior colliculus: a site for visual calibration of the neural representation of auditory space in the barn owl. J Neurosci 13:4589-4608.

Brainard MS, Knudsen EI (1995) Dynamics of visually guided auditory plasticity in the optic tectum of the barn owl. J Neurophysiol 73:595-614.

Castillo PE, Weisskopf MG, Nicoll RA (1994) The role of $\mathrm{Ca}^{2+}$ channels in hippocampal mossy fiber synaptic transmission and long-term potentiation. Neuron 12:261-269.

Doupe AJ, Kuhl PK (1999) Birdsong and human speech: common themes and mechanisms. Annu Rev Neurosci 22:567-631.

Fagiolini M, Hensch TK (2000) Inhibitory threshold for critical-period activation in primary visual cortex. Nature 404:183-186.

Feldman DE (2000) Inhibition and plasticity. Nat Neurosci 3:303-304.

Feldman DE, Knudsen EI (1998a) Experience-dependent plasticity and the maturation of glutamatergic synapses. Neuron 20:1067-1071.

Feldman DE, Knudsen EI (1998b) Pharmacological specialization of learned auditory responses in the inferior colliculus of the barn owl. J Neurosci 18:3073-3087.

Feldman DE, Brainard MS, Knudsen EI (1996) Newly learned auditory responses mediated by NMDA receptors in the owl inferior colliculus. Science 271:525-528.

Fox K (1992) A critical period for experience-dependent synaptic plasticity in rat barrel cortex. J Neurosci 12:1826-1838.

Fujita I, Konishi M (1991) The role of GABAergic inhibition in processing of interaural time difference in the owl's auditory system. J Neurosci 11:722-739.

Gao WJ, Newman DE, Wormington AB, Pallas SL (1999) Development of inhibitory circuitry in visual and auditory cortex of postnatal ferrets: immunocytochemical localization of GABAergic neurons. J Comp Neurol 409:261-273.

Gao WJ, Wormington AB, Newman DE, Pallas SL (2000) Development of inhibitory circuitry in visual and auditory cortex of postnatal ferrets: immunocytochemical localization of calbindin- and parvalbumincontaining neurons. J Comp Neurol 422:140-157.

Hata Y, Tsumoto T, Stryker MP (1999) Selective pruning of more active afferents when cat visual cortex is pharmacologically inhibited. Neuron 22:375-381

Hensch TK, Fagiolini M, Mataga N, Stryker MP, Baekkeskov S, Kash SF (1998) Local GABA circuit control of experience-dependent plasticity in developing visual cortex. Science 282:1504-1508.

Huang ZJ, Kirkwood A, Pizzorusso T, Porciatti V, Morales B, Bear MF, Maffei L, Tonegawa S (1999) BDNF regulates the maturation of inhibition and the critical period of plasticity in mouse visual cortex. Cell 98:739-755.

Hyde PS, Knudsen EI (2000) Topographic projection from the optic tectum to the auditory space map in the inferior colliculus of the barn owl. J Comp Neurol 421:146-160.

Isaac JT, Nicoll RA, Malenka RC (1999) Silent glutamatergic synapses in the mammalian brain. Can J Physiol Pharmacol 77:735-737.

Issa NP, Trachtenberg JT, Chapman B, Zahs KR, Stryker MP (1999) The critical period for ocular dominance plasticity in the Ferret's visual cortex. J Neurosci 19:6965-6978.

Iyengar S, Viswanathan SS, Bottjer SW (1999) Development of topography within song control circuitry of zebra finches during the sensitive period for song learning. J Neurosci 19:6037-6057.

Kakizawa S, Yamasaki M, Watanabe M, Kano M (2000) Critical period for activity-dependent synapse elimination in developing cerebellum. J Neurosci 20:4954-4961.

Katz LC (1999) What's critical for the critical period in visual cortex? Cell 99:673-676.
Katz LC, Shatz CJ (1996) Synaptic activity and the construction of cortical circuits. Science 274:1133-1138.

King AJ (1999) Sensory experience and the formation of a computational map of auditory space in the brain. BioEssays 21:900-911.

Kirkwood A, Bear MF (1994) Hebbian synapses in visual cortex. J Neurosci 14:1634-1645

Kirkwood A, Lee HK, Bear MF (1995) Co-regulation of long-term potentiation and experience-dependent synaptic plasticity in visual cortex by age and experience. Nature 375:328-331.

Kirkwood A, Rioult MC, Bear MF (1996) Experience-dependent modification of synaptic plasticity in visual cortex. Nature 381:526-528.

Knudsen EI (1994) Supervised learning in the brain. J Neurosci 14:3985-3997.

Knudsen EI (1999) Mechanisms of experience-dependent plasticity in the auditory localization pathway of the barn owl. J Comp Physiol 185:305-321.

Knudsen EI, Knudsen PF (1990) Sensitive and critical periods for visual calibration of sound localization by barn owls. J Neurosci 63:131-149.

Knudsen EI, Konishi M (1978) A neural map of auditory space in the owl. Science 200:795-797.

Komatsu Y (1983) Development of cortical inhibition in kitten striate cortex investigated by a slice preparation. Dev Brain Res 8:136-139.

Lein ES, Finney EM, McQuillen PS, Shatz CJ (1999) Subplate neuron ablation alters neurotrophin expression and ocular dominance column formation. Proc Natl Acad Sci USA 96:13491-13495.

Luhmann HJ, Prince DA (1991) Postnatal maturation of the GABAergic system in rat neocortex. J Neurophysiol 65:247-263.

Maccaferri G, Toth K, McBain CJ (1998) Target-specific expression of presynaptic mossy fiber plasticity. Science 279:1368-1370.

Micheva KD, Beaulieu C (1995) Postnatal development of GABA neurons in the rat somatosensory barrel cortex: a quantitative study. Eur J Neurosci 7:419-430.

Micheva KD, Beaulieu C (1997) Development and plasticity of the inhibitory neocortical circuitry with an emphasis on the rodent barrel field cortex: a review. Can J Physiol Pharmacol 75:470-478.

Mori K (1997) Across-frequency nonlinear inhibition by GABA in processing of interaural time difference. Hear Res 111:22-30.

Nicoll RA, Malenka RC (1999) Expression mechanisms underlying NMDA receptor-dependent long-term potentiation. Ann NY Acad Sci 868:515-525.

Nordeen KW (1997) Neural correlates of sensitive periods in avian song learning. Ann NY Acad Sci 807:386-400.

Nowak L, Bregestovski P, Ascher P, Herbet A, Prochiantz A (1984) Magnesium gates glutamate-activated channels in mouse central neurones. Nature 307:462-465.

O'Leary DD, Ruff NL, Dyck RH (1994) Development, critical period plasticity, and adult reorganizations of mammalian somatosensory systems. Curr Opin Neurobiol 4:535-544.

Rhoades RW, Strang V, Bennett-Clarke CA, Killackey HP, Chiaia NL (1997) Sensitive period for lesion-induced reorganization of intracortical projections within the vibrissae representation of rat's primary somatosensory cortex. J Comp Neurol 389:185-192.

Schacher S, Wu F, Sun ZY (1997) Pathway-specific synaptic plasticity: activity-dependent enhancement and suppression of long-term heterosynaptic facilitation at converging inputs on a single target. J Neurosci 17:597-606.

Schlaggar BL, Fox K, O'Leary DD (1993) Postsynaptic control of plasticity in developing somatosensory cortex. Nature 364:623-626.

Urban NN, Barrionuevo G (1996) Induction of hebbian and nonHebbian mossy fiber long-term potentiation by distinct patterns of high-frequency stimulation. J Neurosci 16:4293-4299.

Zheng W, Knudsen EI (1999) Functional selection of adaptive auditory space map by $\mathrm{GABA}_{\mathrm{A}}$-mediated inhibition. Science 284:962-965. 